\title{
ASSESSMENT ON KNOWLEDGE REGARDING HUMAN PAPILLOMAVIRUS VACCINATION AMONG MAHSA UNIVERSITY STUDENTS
}

\author{
NADIATUL AZRA AHMAD MAZLAN*, NG XIN HUI
}

Department of Pharmacy Practice, Faculty of Pharmacy, MAHSA University, Puchong, Selangor, Malaysia.*Email: azra@mahsa.edu.my

Received: 2 March 2018, Revised and Accepted: 16 March 2018

ABSTRACT

Objective: This study aimed to assess the knowledge of undergraduate students of MAHSA University on human papillomavirus (HPV) vaccination.

Methods: The cross-sectional study was conducted using a self-administered questionnaire among 350 local undergraduate students recruited by convenience sampling. The survey was conducted in English and consisted of questions on demographic data and 14 questions on knowledge toward HPV vaccination. Verbal consent was obtained from the participants beforehand, and their participation was voluntary and anonymous.

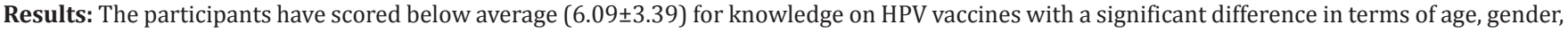
and program of the study. Students from medicine, dentistry, and biomedical science tend to have better mean knowledge score ( $7.39 \pm 2.99)$ with $25 \%$ scored 10 and above. The non-health-care students showed insignificant lower mean knowledge score of $4.17 \pm 2.06$, respectively.

Conclusion: This study has demonstrated moderate level HPV vaccine knowledge toward HPV vaccination among university students with majority posed background of health-related knowledge.

Keywords: Human papillomavirus, Cervical cancer, University students, Vaccine.

(C) 2018 The Authors. Published by Innovare Academic Sciences Pvt Ltd. This is an open access article under the CC BY license (http://creativecommons. org/licenses/by/4. 0/) DOI: http://dx.doi.org/10.22159/ajpcr.2018.v11s3.30032

\section{INTRODUCTION}

Human papillomavirus (HPV) is the most common viral infection of the reproductive system, and it is one of the most common sexually transmitted diseases [1,2]. Approximately 99\% of the cervical cancer cases are contributed by HPV infection [3]. Common high-risk HPV strains, which are HPV 16 and 18, contribute $70 \%$ of cervical cancers and also cancers of anus, vagina, vulva, penis, and head and neck cancers [4]. There is less probability from low-risk HPV strains to cause cancer; however, HPV strains 6 and 11 can contribute $90 \%$ occurrence of genital warts [5].

Administration of prophylactic vaccine and elimination of sexual risk factor are the primary prevention of HPV infection [6]. The Food and Drug Administration has approved three vaccines for preventing HPV infections, which are Gardasil ${ }^{\circledR}$ (quadrivalent HPV vaccine), Gardasil ${ }^{\circledR-9}$ (nanovalent HPV vaccine), and Cervarix ${ }^{\circledR}$ (bivalent HPV vaccine) and administered through 3 injections intramuscularly. According to the National Cancer Institute high-risk HPV strains, HPV 16 and 18 can be prevented with these three HPV vaccines. The Advisory Committee on Immunization Practices (ACIP) recommended the routine use of Gardasil $^{\circledR}$ in females aged 11 or 12 years old $[7,8]$.

Shafiee, in his study, pointed out that $30-60 \%$ of all sexually active adults will acquire HPV infection at some point in their lives and highest incidence occurred among adult aged between 18 and 28 years old [10]. Administration of HPV vaccine after first sexual intercourse reported lessen efficacy of HPV vaccine [11]. Persistent infection with high-risk HPV genotypes leads to cancers though most of the HPV infections are self-limiting. Another study showed that younger age women, use of contraceptives, alcohol drinking, and smoking have a higher risk of HPV infection [12].

In Malaysia, the Ministry of Health $(\mathrm{MOH})$ has implemented the National HPV vaccination program since 2010, which targeted for Form 1 female students and free for three complete doses [13]. However, there are limited studies about HPV vaccine knowledge and its attitude among university students which include male and female in Malaysia. The studies carried out in Malaysia previously include a population of non-healthcare university students, mother, secondary school girls, and female adults $[10,14-16]$. This study aims to determine the knowledge of HPV vaccination among MAHSA University students.

\section{METHODS}

The questionnaireswere adapted from two studies conducted previously on two different populations $[10,17]$. Questions on demographic profile were outlined based on literature review of numerous similar studies. The HPV vaccination knowledge statements were consisted of 15 questions with the options of true, false, and unsure. In knowledge section, one point was given to a correct answer by respondents. The knowledge score for the respondents was categorized into poor, moderate, and good knowledge. The questionnaire was pilot tested and resulted in Cronbach's alpha of 0.619 .

The questionnaires were made available to all MAHSA university students studying bachelor degree regardless of age. Only Malaysian nationalities were included. Bachelor degree students who were not available in the campus and in semester break were excluded from the study.

The completed questionnaires were analyzed using the SPSS Statistical software version 22. Descriptive statistics were used to analyze the frequency, percentage, and mean of the data. Independent t-test and ANOVA were used in comparison of knowledge scores for demographic variables.

\section{RESULTS}

\section{Sociodemographic characteristics}

From the data collected from university registry office, 1757 Malaysian students were registered for bachelor's studies regardless of year and courses during the time of this study. A number of 350 questionnaires 
were distributed randomly in classes, libraries, and university cafes to meet the minimum sample size. The demographic profile is tabulated in Table 1. Two-thirds of the respondents were female and aged 1823 years old. Almost all respondents were from health-care-related courses $(90 \%)$.

\section{Knowledge on HPV vaccine brand name}

A huge amount of $84.6 \%(n=296)$ responded positive when asked on the availability of HPV vaccines in Malaysia regardless of courses or gender. They were unsure on the brand name, but they knew the MOH campaign on HPV vaccination program which started in 2010. The number of respondents recognized Cervarix ${ }^{\circledR}$ as HPV vaccine was higher than Gardasil ${ }^{\circledR}$, with $20.3 \%$ and $4.7 \%$, respectively. Only $2.4 \%$ replied that both brands are available in Malaysia which is true.

Despite major campaign by the ministry to provide free school-based vaccination to Form 1 secondary school students (irrespective of age), $34.5 \%$ of participants believe that the vaccine is only to be taken at 18 years old and above and $26.4 \%$ of respondents were uncertain on

Table 1: Demographic profile of respondents $(n=350)$

\begin{tabular}{ll}
\hline Demographic variable & $\mathbf{n}(\%)$ \\
\hline Gender & \\
Male & $110(31.4)$ \\
Female & $240(68.6))$ \\
Age & \\
$18-20$ & $59(16.9)$ \\
$21-23$ & $220(62.9)$ \\
$24-26$ & $65(18.6)$ \\
>27 & $6(1.7)$ \\
Ethnicity & \\
Malay & $100(28.6)$ \\
Chinese & $171(48.9)$ \\
Indian & $54(15.4)$ \\
Other & $25(7.1)$ \\
Program of the study & \\
Medicine & $60(17.1)$ \\
Dentistry & $61(17.4)$ \\
Pharmacy & $60(17.1)$ \\
Biomedical science & $58(16.6)$ \\
Physiotherapy & $55(15.7)$ \\
Medical imaging & $21(6.0)$ \\
Environmental health & $4(1.1)$ \\
Engineering & $9(2.6)$ \\
Business & $22(6.3)$ \\
\hline
\end{tabular}

the recommended age (Table 2). A smaller number of respondents knew that HPV vaccination is available to both genders (19.3\%) since the free vaccination was only delivered for Malaysian women aged 1826. More than half $(58.5 \%)$ recognizes the need to take three injections of the vaccine over 6 months' duration.

\section{Knowledge on HPV vaccine uses}

An analysis of correct responses to the survey questionnaires was performed (Table 2). A vast majority knew that HPV vaccines protect against cervical cancer, but only $38.5 \%$ noticed that HPV vaccination only protects against certain strains of virus that causes cervical cancer. Moreover, similar numbers of participants were unsure on numerous strains of HPV. About $21.3 \%$ of respondents thought that HPV vaccination acts as preventive measures against all sexually transmitted infections (STI), whereas $46.3 \%$ that aware of the HPV vaccination is only for the most common STI.

Nearly half $(44.6 \%)$ knew that this vaccine will protect them from genital warts, but $17.9 \%$ falsely believed the vaccine as genital warts treatment. Only $27 \%$ and $23 \%$ knew that HPV vaccination will not treat genital warts and genital herpes, respectively. Only few respondents (47\%) noticed that HPV vaccination is best taken before first sexual activities and aware that the effects of vaccination pre- and post- sexual activities were unsimilar. The participants (53.4\%) knew that the HPV vaccination is important to women with one sexual partner as well as for women with multiple partners.

A higher percentage (42.9\%) of respondents were uncertain that women previously vaccinated further pap smear and $48.3 \%$ realized that pap smear test acts as extra protective measures in addition to HPV vaccination since it acts as early detection or screening procedure of cervical cancer.

Knowledge scores were reported in mean with a range between 0 and 15 (Table 3). Interestingly, despite the high percentage of positive response toward HPV vaccination, only $16.6 \%$ of 296 participants showed a good knowledge score with one-third poor score. The mean score was moderate with $6.09 \pm 3.39$ (mean \pm standard deviation [SD]).

Three sociodemographic variables (age, gender, and courses) were analyzed in determining their association that could influence their knowledge score on HPV vaccination (Table 4). There was a good knowledge score with an increase in age. A significant difference was found in knowledge scores between genders despite both genders displayed the moderate score of $5.81 \pm 3.70$ and $6.82 \pm 3.58$ for male and

Table 2: Knowledge of the respondents toward HPV vaccination $(n=296)$

\begin{tabular}{|c|c|c|c|c|}
\hline \multirow[t]{2}{*}{ Statements } & \multirow[t]{2}{*}{ Answer } & \multicolumn{3}{|l|}{ n (\%) } \\
\hline & & Answer correctly & Answer incorrectly & Unsure \\
\hline HPV vaccine protects against cervical cancer. & True & $226(76.4)$ & $2(0.7)$ & $68(23.0)$ \\
\hline $\begin{array}{l}\text { HPV vaccine protects against all types of the virus that causes cervical } \\
\text { cancer. }\end{array}$ & False & $114(38.5)$ & $68(23.0)$ & $114(38.5)$ \\
\hline HPV vaccine protects against all sexually transmitted infections. & False & $137(46.3)$ & $63(21.3)$ & $96(32.4)$ \\
\hline HPV vaccine can only be taken after the age of 18 years old. & False & $116(39.2)$ & $102(34.5)$ & $78(26.4)$ \\
\hline HPV vaccine is currently available to both men and women. & True & $57(19.3)$ & $127(42.9)$ & $112(37.9)$ \\
\hline HPV vaccination is taken as three injections over 6 months. & True & $173(58.5)$ & $19(6.4)$ & $104(35.1)$ \\
\hline HPV vaccine can treat genital warts. & False & $80(27.0)$ & $51(17.2)$ & $165(55.7)$ \\
\hline HPV vaccine offers protection against genital warts. & True & $132(44.6)$ & $27(9.1)$ & $137(46.3)$ \\
\hline HPV vaccine does not protect against genital herpes. & True & $68(23.0)$ & $66(22.3)$ & $162(54.7)$ \\
\hline Women who receive HPV vaccine need less frequent pelvic examination. & False & $120(40.5)$ & $34(11.5)$ & $142(48.0)$ \\
\hline Women who receive HPV vaccine do not have to get Pap smear. & False & $143(48.3)$ & $26(8.8)$ & $127(42.9)$ \\
\hline HPV vaccine is best taken before starting to have sexual activities. & True & $139(47.0)$ & $59(19.9)$ & $98(33.1)$ \\
\hline $\begin{array}{l}\text { HPV vaccines have the same effect whether the female takes it before or } \\
\text { after being infected with HPV. }\end{array}$ & False & $141(47.6)$ & $22(7.4)$ & $133(44.9)$ \\
\hline
\end{tabular}

HPV: Human papillomavirus 
Table 3: Knowledge mean score among participants

\begin{tabular}{|c|c|c|c|c|c|}
\hline $\begin{array}{l}\text { Knowledge } \\
\text { mean score }\end{array}$ & \multicolumn{2}{|c|}{ Poor 0-4 } & Moderate 5-9 & \multicolumn{2}{|c|}{ Good 10-15 } \\
\hline Frequency (\%) & \multicolumn{2}{|c|}{$96(32.4)$} & $151(51.0)$ & \multicolumn{2}{|c|}{$49(16.6)$} \\
\hline \multicolumn{6}{|c|}{$\begin{array}{l}\text { One point was given to correct answer for each question. The knowledge score } \\
\text { was categorized into poor, moderate, and good knowledge }\end{array}$} \\
\hline \multicolumn{6}{|c|}{$\begin{array}{l}\text { Table 4: Correlations between knowledge mean score and } \\
\text { sociodemographic variables }\end{array}$} \\
\hline Demographic v & iables & Kn & edge score Mea & $\mathrm{D}^{*}$ & $\mathbf{p}$ \\
\hline \multicolumn{6}{|l|}{ Age } \\
\hline $18-20$ & & 5.8 & 69 & \multirow{4}{*}{\multicolumn{2}{|c|}{0.027}} \\
\hline $21-23$ & & 5.8 & 37 & & \\
\hline $24-26$ & & 7.0 & 70 & & \\
\hline$>27$ & & 8.0 & 90 & & \\
\hline \multicolumn{6}{|l|}{ Gender } \\
\hline Male & & 5.8 & 70 & \multirow{2}{*}{\multicolumn{2}{|c|}{0.016}} \\
\hline Female & & 6.8 & 58 & & \\
\hline \multicolumn{6}{|c|}{ Program of the study } \\
\hline Medicine & & 7.4 & 25 & \multirow{9}{*}{\multicolumn{2}{|c|}{$<0.001$}} \\
\hline Dentistry & & 7.5 & 85 & & \\
\hline Pharmacy & & 5.7 & & & \\
\hline Biomedical sc & & 7.1 & 83 & & \\
\hline Physiotherapy & & 2.2 & 37 & & \\
\hline Medical imagi & & 6.2 & 67 & & \\
\hline Environmenta & ealth & 3.0 & 71 & & \\
\hline Engineering & & 6.0 & 07 & & \\
\hline Business & & 3.5 & 55 & & \\
\hline
\end{tabular}

female respondents, respectively. Results shown in Table 4 were similar between three health-care courses (medicine, dentistry, and biomedical science) with an average knowledge score of $7.39 \pm 2.99(n=168)$ and medical imaging students $(6.27 \pm 2.67 ; n=15)$ showed slightly higher knowledge score compared to pharmacy students $(5.79 \pm 3.10 ; n=48)$. Participants from non-health-care courses showed poor-to-moderate knowledge score of $4.17 \pm 2.03(n=23)$.

\section{DISCUSSION}

This study assessed on knowledge of MAHSA university students on HPV vaccination by random selection. In this study, the respondents were mainly made up from the age of 21 to 23 years old $(62.9 \%)$. The young adult is the main concern in this study as more than half of the sexual-transmitted disease-infected population are from the age range of 15 to 24 years old [18]. The awareness level of $84.6 \%$ was observed in this study which was similar to that reported by Blodt and his research group Blödt et al. [19]. The percentages reported by the previous studies conducted in Malaysia were as low as $7.8 \%$ and up to $76.3 \%[3,10,15,20]$.

There was moderate knowledge mean score seen in this study which was similarly noted among pre-university students [1]. Most of the students $(76.4 \%)$ knew the purpose of HPV vaccination which is similar to the other two studies conducted in Malaysia with $67.9 \%$ and $73.2 \%$, respectively $[1,10]$. A low number of $23 \%$ of students were seen to be unaware of the function of HPV vaccination despite the HPV schoolbased vaccination program was launched in 2010 .

Although $44.6 \%$ knew that the vaccine also protects against genital warts and it was higher compared to study done among Belgian students (19.4\%) [21] and Sadry research group [22], the percentage was expected to be higher since most of the respondents (92\%) were from health-care-related courses. HPV vaccination is well known for protection against cervical cancer compared to genital warts and genital herpes though both are caused by certain strains of HPV [22].
Higher awareness of cervical cancer protection by HPV vaccine is due to common non-technical term for HPV vaccines which is "the cervical cancer vaccine" which targeted to young women at the aged 26 and below rather than for men [15]. With regard to vaccination among men, $42.9 \%$ of students' misunderstood that the uses of HPV vaccine are only for women, and it has been demonstrated that Gardasil ${ }^{\circledR}$ was shown to prevent cancer and HPV-related diseases in men [23].

Condoms may lower the chances of suffering HPV for sexually active adults, but it does not eliminate the risk which not gives a full protection [24].

In this study, almost half of the participants answered correctly that the course of HPV vaccination is three injections over 6 months and approximate number unsures with this statement. Similar pattern observed among female students in Lebanon and lower percentage $(36.2 \%)$ in Penang $[3,17]$. ACIP initiated two doses of HPV vaccination for girls and boys between ages 9 and 14 years and recommended three doses for 15-26 years old, whereas complete regimen of 3 doses within 6 months duration in Malaysia [1,9].

Nearly half of the respondents demonstrated good understanding that full benefits of the vaccination are available only for those who taken it before their first sexual encounter. Since HPV infection is transmitted directly, the onset of infection may start immediately after sexual intercourse [5]. However, a positive result was shown in studies conducted among college students in Lebanon and Belgium with higher percentages of $66 \%$ and $83 \%$, respectively $[17,21]$.

The participants (53.4\%) knew that the HPV vaccination is important to women with one sexual partner as well as for women with multiple partners. The reported positive percentage of respondents' knowledge was lower compared to result in a study done in Toronto that most of respondents $(87.8 \%)$ aware that the number of sexual partners is not a determinant factor for HPV vaccination [22]. Adequate information regarding the benefits of it despite sexual inactive should be addressed as it could be one of the main barriers for unintended of vaccination [2]. Moreover, having less number of sexual partner helps in reducing the risk of HPV infection [15].

Furthermore, approximately half of the respondents knew the need of Pap smear screening even after HPV vaccination. However, similar numbers of respondents $(42.9 \%)$ hesitate that pap smear could provide extra benefit post vaccination. In a study by Wong and Sam among female university students, more than half $(57.2 \%)$ heard of pap smear test, but only minority of them could identify the use of pap smear [20]. Thus, misinformation has led to a lower rate of cervical cancer screening among vaccinated female population compared to unvaccinated group $[25,26]$. It is critical as HPV vaccination together with regular Pap smear test effective in preventing mortality and morbidity brought by HPV infections [21].

Knowledge scores among health related students were found slightly higher though moderate compared to non-health-related programmes. Similar results were found in college female students in Lebanon [17]. Among all the programmes involved in this study, students from physiotherapy studies showed the lowest mean knowledge score [2.21 \pm 2.37$]$. This may be due to syllabus learnt which focus on human anatomy, rather than physiology. In a study run in obstetrics clinic, the knowledge of HPV vaccines and HPV immunization program was significantly associated with the level of education and ages [14].

\section{CONCLUSION}

This study has demonstrated moderate level HPV vaccine knowledge toward HPV vaccination among university students with majority pose background of health-related knowledge. Besides, the survey was a cross-sectional study instead of longitudinal, and hence, unable to provide information on changes of findings over time. Knowledge is likelihood to associate with attitude toward HPV vaccination, and thus, it is important to stress on the dissemination of information related to HPV vaccination among young adults. 


\section{FUNDING SOURCES}

This research did not receive any specific grant from funding agencies in the public, commercial, or non-profit sectors.

\section{CONFLICTS OF INTEREST}

There are no conflicts of interest to declare.

\section{REFERENCES}

1. Kwang NB, Yee CM, Shan LP, Teik CK, Chandralega KN, Abdul Kadir AK, et al. Knowledge, perception and attitude towards human papillomavirus among pre-university students in Malaysia. Asian Pac J Cancer Prev 2014;15:9117-23.

2. Jain N, Euler GL, Shefer A, Lu P, Yankey D, Markowitz L, et al. Human papillomavirus (HPV) awareness and vaccination initiation among women in the united states, national immunization survey-adult 2007. Prev Med 2009;48:426-31.

3. Khoo CL, Teoh S, Rashid AK, Zakaria UU, Mansor S, Salleh FN, et al. Awareness of cervical cancer and HPV vaccination and its affordability among rural folks in Penang Malaysia. Asian Pac J Cancer Prev 2011;12:1429-33.

4. Fu CJ, Pan XF, Zhao ZM, Saheb-Kashaf M, Chen F, Wen Y, et al. Knowledge, perceptions and acceptability of HPV vaccination among medical students in Chongqing, china. Asian Pac J Cancer Prev 2014; 15:6187-93.

5. De Vincenzo R, Conte C, Ricci C, Scambia G, Capelli G. Long-term efficacy and safety of human papillomavirus vaccination. Int J Women's Health 2014;6:999-1010.

6. Guvenc G, Seven M, Akyuz A. Health belief model scale for human papilloma virus and its vaccination: Adaptation and psychometric testing. J Pediatr Adolesc Gynecol 2016;29:252-8.

7. National Cancer Institute. Human Papillomavirus (HPV) Vaccines. Available from: http://www.cancer.gov/about-cancer/causes-prevention/ risk/infectious-agents/hpv-vaccine-fact-sheet. [Last accessed on 2015 Oct 03].

8. Sundstrom B, Carr LA, DeMaria AL, Korte JE, Modesitt SC, Pierce JY. Protecting the next generation: Elaborating the health belief model to increase HPV vaccination among college-age women. Soc Mark Q 2015;21:173-88.

9. Centers for Disease Control and Prevention (CDC). Recommendations on the use of quadrivalent human papillomavirus vaccine in males advisory committee on immunization practices (ACIP), 2011. MMWR Morb Mortal Wkly Rep 2011;60:1705-8.

10. Shafiee MN, Chew KT, Kampan N, Lim PS. Perception, knowledge and attitude towards human papillomavirus infection and vaccination for cervical cancer prevention among university students. Brunei Int Med J 2013;9:315-24.

11. Garnett GP, Kim JJ, French K, Goldie SJ. Chapter 21: Modelling the impact of HPV vaccines on cervical cancer and screening programmes. Vaccine 2006;24:178-86
12. Silva KC, Rosa ML, Moyse N, Afonso LA, Oliveira LH, Cavalcanti $\mathrm{SM}$, et al. Risk factors associated with human papillomavirus infection in two populations from Rio de Janeiro, Brazil. Mem Inst Oswaldo Cruz 2009;104:885-91

13. Ministry of Health Malaysia. Cervical Cancer Vaccine. Gardasil ${ }^{\circledR}$ And Cervarix ${ }^{\circledR}$ Health Technology Assessment Section, Medical Development Division Ministry of Health Malaysia, Report No. 008/2011; 2011.

14. Ezat SW, Hod R, Mustafa J, Mohd Dali AZ, Sulaiman AS, Azman A, et al. National HPV immunisation programme: Knowledge and acceptance of mothers attending an obstetrics clinic at a teaching hospital, Kuala Lumpur. Asian Pac J Cancer Prev 2013;14:2991-9.

15. Al-Naggar RA, Bobryshev YV, Al-Jashamy K, Al-Musli M. Practice of HPV vaccine and associated factors among school girls in Melaka, Malaysia. Asian Pac J Cancer Prev 2012;13:3835-40.

16. Rashwan HH, Saat NZ, Abd Manan DN. Knowledge, attitude and practice of Malaysian medical and pharmacy students towards human papillomavirus vaccination. Asian Pac J Cancer Prev 2012;13:2279-83.

17. Dany M, Chidiac A, Nassar AH. Human papillomavirus vaccination: Assessing knowledge, attitudes, and intentions of college female students in Lebanon, a developing country. Vaccine 2015;33:1001-7.

18. Illozumba UO. HPV Vaccination Knowledge and Attitude amongst Students in Two and Four Year Colleges in Atlanta, Georgia [M.S. Thesis]. Univ. Emory; 2011.

19. Blödt S, Holmberg C, Müller-Nordhorn J, Rieckmann N. Human papillomavirus awareness, knowledge and vaccine acceptance: A survey among 18-25 year old male and female vocational school students in Berlin, Germany. Eur J Public Health 2012;22:808-13.

20. Wong LP, Sam IC. Ethnically diverse female university students' knowledge and attitudes toward human papillomavirus (HPV), HPV vaccination and cervical cancer. Eur J Obstet Gynecol Reprod Biol 2010;148:90-5.

21. Deriemaeker H, Michielsen D, Reichman G, Devroey D, Cammu H. Knowledge about human papillomavirus and the human papillomavirus vaccine in Belgian students. Cent Eur J Urol 2014;67:410-7.

22. Sadry SA, De Souza LR, Yudin MH. The impact of ethnicity on awareness and knowledge of and attitudes towards the human papillomavirus and vaccine among adult women. J Obstet Gynaecol Can 2013;35:995-1003.

23. Giuliano AR, Palefsky JM, Goldstone S, Moreira ED Jr., Penny ME, Aranda C, et al. Efficacy of quadrivalent HPV vaccine against HPV infection and disease in males. N Engl J Med 2011;364:401-11.

24. Katz ML, Krieger JL, Roberto AJ. Human papillomavirus (HPV): College male's knowledge, perceived risk, sources of information, vaccine barriers and communication. J Mens Health 2011;8:175-84.

25. Al-Dubai SA, Alshagga MA, Al-Naggar RA, Al-Jashamy K, Baobaid MF, Tuang CP, et al. Knowledge, attitudes and barriers for human papilloma virus (HPV) vaccines among Malaysian women. Asian Pac J Cancer Prev 2010;11:887-92.

26. Budd AC, Brotherton JM, Gertig DM, Chau T, Drennan KT, Saville M, et al. Cervical screening rates for women vaccinated against human papillomavirus. Med J Aust 2014;201:279-82. 